\title{
Insights into the state of affairs and possible ways to improve secondary material waste management
}

\author{
Evgeniy Velichko, ${ }^{1, *}$, and Eduard Tskhovrebov ${ }^{2}$ \\ ${ }^{1}$ Moscow State University of Civil Engineering, Yaroslavskoe shosse, 26, Moscow, 129337, Russia \\ ${ }^{2}$ Federal State Autonomous Research Institute Environmental Industrial Policy Center, Mytishchi, \\ Moscow region, Russia
}

\begin{abstract}
The paper focuses on the statutory regulation and ways of improving secondary materials management, their use as secondary raw materials for the manufacture of goods, provision of works, services, as well as power generation. It is shown that due to the economic factor, only readily available and valuable waste, particularly, ferrous and non-ferrous metal scrap and waste, high-grade paper, pure textiles, plastic and wood waste, glass scrap, some mineral waste from the electric power, metal, chemical industries, construction and demolition of buildings, structures, construction materials industry are injected back into the economy. Obviously, better legal, economic, organizational and technical aspects of recycling will help tackle the fundamental environmental challenges currently faced by the Russian Federation, as well as contribute to its policy geared towards conservation of strategic natural resources and long-term sustainable economic development.
\end{abstract}

\section{Introduction}

The ever-growing hazardous industrial and household waste dumps, which take their toll on the environment, represent the today's challenge for nature preservation due to the increasing man-made environmental, sanitary and epidemiological impact on nature causing a dire threat to environmental safety. This factor spurs the search for new and justified approaches to lawmaking, planning the effective systems of waste sorting, treatment, disposal of waste generated by manufacture and consumption, increasing the share of secondary materials in industrial production and other economic activities [1-3].

\section{Problems}

The Russian Federation possesses vast resources of secondary materials (secondary raw materials) as annual waste generated and accumulated from production and consumption, which can be described as renewable raw, material, fuel and energy resources. According to

\footnotetext{
Corresponding author: pct44@yandex.ru
} 
expert estimates, the amount of secondary raw materials in the industry is 2.73 bn tons per year, with $90 \%$ generated from mining and mineral dressing [4-10].

Secondary raw materials are used by almost all national industries. However, their amounts and levels of use are largely different and depend on waste value, the environmental situation arising from handling such materials as environmental pollutants and, most importantly, on the emerging economic conditions that determine the rate of return for each particular recycler.

Meanwhile, the EU and Japan adopted legal instruments and economic conditions driving waste disposal and recycling over one decade ago.

The diagram of waste and secondary materials management is shown in Figure 1.

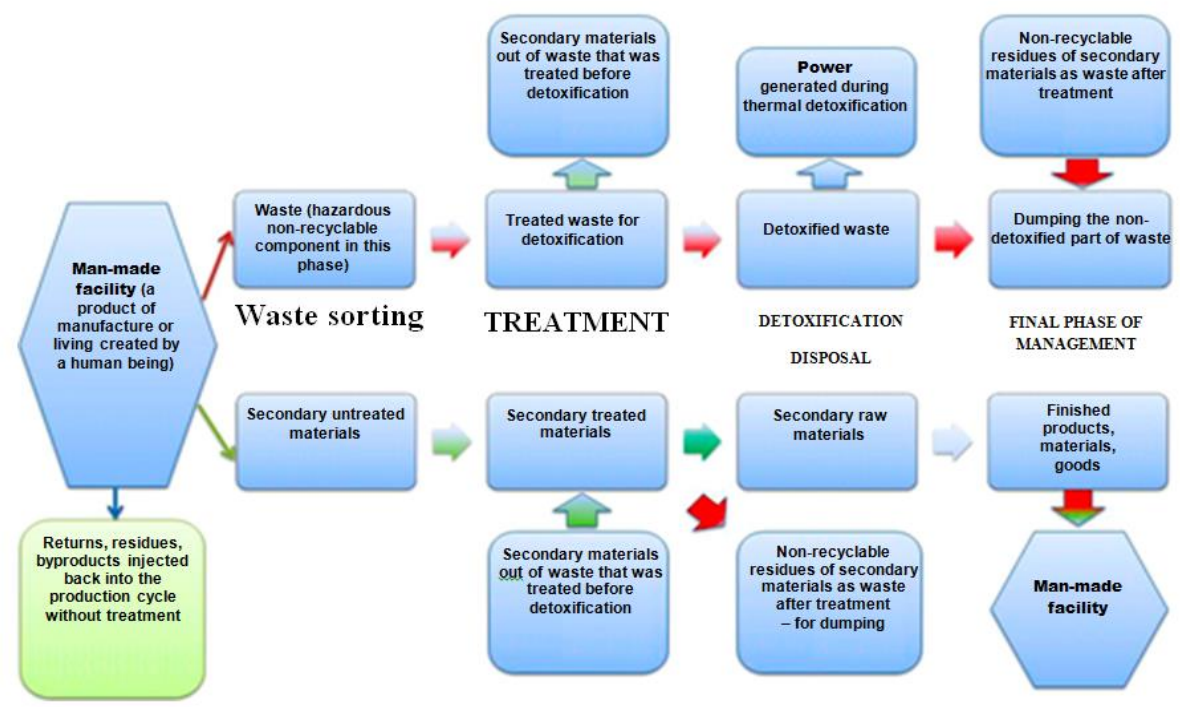

Fig. 1. Phases of waste and secondary materials management

\section{Results}

The obtained insights into the system of handling secondary raw materials (in particular, in construction and other industries, based on the findings of the Federal State Autonomous Research Institute Environmental Industrial Policy Center show that due to the economic factor, only readily available and valuable waste, particularly, ferrous and non-ferrous metal scrap and waste, high-grade paper, pure textiles, plastic and wood waste, glass scrap, some mineral waste from the electric power, metal, chemical industries, construction and demolition of buildings, structures, construction materials industry are injected back into the economy.

The today's core factors of poor recycling of secondary raw materials are the following:

- lack of enough incentives for the mass collection and treatment of secondary raw materials in the current economy;

- limited legal acts governing waste management as secondary materials;

- faulty government regulation of secondary raw materials use;

- poor organization of waste collection for further recycling;

- poor awareness of public monitoring in the area of secondary raw materials and the relevant market. 
The easily availability of natural resources in most Russian industries and, consequently, their affordability and low costs vs. global prices, is cited as a core reason explaining the lack of enough incentives to the organization of collection and treatment of secondary raw materials. A negative factor is also high waste collection and treatment (handling, cleaning, sorting, separation, resizing, washing, drying) costs for many types of waste as the primary phase of recycling, which does not ensure an acceptable rate of return for recyclers. This is particularly true for obsolete finished products and their packaging containing such well recyclable materials as ferrous and non-ferrous metals, thermoplastics, rubber, cellulose fiber from wastepaper.

The poor marketability of recycled materials also contributes to fewer incentives to organizing the collection and treatment of some secondary materials, although lower prices compared with products made of "primary" natural raw materials do not always mean that they are of poor quality. In particular, this refers to a wide range of products made of waste thermoplastics and rubber (packaging, garden hoses, polymer film, technical products from thermoplastic and rubber), recycled motor oils, toilet paper made from waste paper, etc. The demand for such products often remains quite low even despite strong price cuts, down to $50 \%$ or more.

Consequently, scarce custom recyclers are not game changers in energy and resource conservation, environmental safety, reduction in the ever-growing production and household waste footprint. The share of recycled waste used in construction is about one third, and for a number of categories in other industries it is far less.

The sketchy legal and regulatory framework on waste management as secondary raw materials is expressed in the lack of legislative and regulatory provisions governing:

fundamental state policies on the organization of waste collection for further recycling, development of the recycled raw materials market;

responsibility of businesses and individuals, as well as administrative authorities at the federal, regional and local levels, for the collection and use of waste as secondary materials, including because of the lack of a clear division between the concepts of "waste" and "secondary materials";

procedural issues of classifying waste as secondary raw materials when setting limits and charging fees for its storage.

These are barriers to a resource-saving policy in the framework of the government environmental strategy, which create economic problems for businesses in terms of setting limits and charging fees for waste storage. In particular, businesses cannot always prove that certain types of waste are intended for recycling, and, therefore, are forced to pay for temporary waste storage prior to its reuse as raw materials.

The imperfect government regulation is reflected by the limited regulatory impact of economic incentives assisting the circulation of secondary raw materials, as well as the imperfect and limited special administrative instruments of state regulation governing the collection and treatment of secondary raw materials.

The system of licensing the procurement and treatment of secondary raw materials is largely burdensome for small businesses, since it requires them to have own production facilities, recycling equipment and expensive custom laboratories. These new requirements have squeezed some small and medium-sized businesses out of the market resulting in fewer players engaged in the collection and procurement of secondary raw materials, production using recycled raw materials.

The regulatory audit of waste management has a pronounced administrative and regulatory nature and, as a rule, does not encourage businesses for waste sorting and disposal, resource saving and use of secondary raw materials. Moreover, the current Russian laws do not obligate businesses to sort, accumulate, treat and dispose of waste for the sake of less waste footprint, sustainability and conservation of natural resources. 
In actual life, the system of waste disposal quotas does not impose any restrictions on the disposal and deposit of waste considered as valuable secondary materials. Here, regional and local initiatives have no legal basis at the federal scale. Waste disposal and recycling fees have, in fact, turned into one of tax varieties that do not boost any economic regulation and stimulation of resource conservation, waste disposal and recycling.

Russia lacks a system of secondary material certification in place. This is particularly relevant for raw polymers, as even small amounts of impurities and contaminants dramatically reduce the quality of secondary raw materials, the service life and capacity of equipment used in the manufacturing of products from recycled raw materials. However, there is no public labeling system for polymers being parts of industrial products made from plastics, which makes it difficult to identify the mentioned waste during its sorting.

The waste classification system in the current version of the Federal Waste Classification Catalog has no resource-conservation targets. For example, the classification of insignificant contamination of packaging or wipes is meticulously detailed and specified in terms of specific substances of 4-5 hazard classes that do not have any strong negative impact on the environment, which only makes it harder to identify a specific type of secondary materials because the classification adopted in the Federal Waste Classification Catalog is not in line with the names of secondary raw categories used in the processing industries.

The key document here, which was highly anticipated during the entire quarter century in the history of modern Russia, is the Strategy for the Development of Industry for the Treatment, Disposal and Detoxification of Production and Consumption Waste until 2030 approved by the Government of the Russian Federation, Decree N 84-p dated 25/01/2018. The document governing the industry-specific strategic planning specifies the creation of a brand new industry, and it is anticipated to tackle ample new tasks, first of all, resource conservation and waste management [10].

\section{Conclusions and recommendations}

The government strategy can be further developed by the new federal law on secondary materials as the key phase of measures for its effective implementation through harmonizing and updating existing waste and secondary materials laws. Establishing a legal format and regulation of management, governance, accounting of secondary materials will purportedly create better conditions for waste collection and recycling for further products, works, services and energy; contribute to strategic non-renewable natural reserve conservation: forest, minerals, bodies of water.

The approximate structure of this federal law may include:

- description of basic concepts related to secondary raw materials;

- definition of objects and subjects of legal regulation;

- legal framework of government policy on secondary materials;

- powers of federal and municipal executive authorities, rights and duties of businesses and individuals in secondary raw materials management;

- legal framework for government regulation and economic incentives for recyclers;

- state and public control in secondary raw materials management;

- types of liability for the breach of related laws.

The effective implementation of this act will contribute to:

- roll-out of program measures in line with the targets described in "Strategy for the Development of Industry for the Treatment, Disposal and Detoxification of Production and Consumption Waste until 2030";

- stepped up use of unpopular secondary materials helping to reduce the waste footprint (first of all, polymers and wood, waste paper, ashes and slag of thermal and power plants, metal scrap, worn out tires, used oils, batteries, electrical devices, etc.); 
- increased share of secondary raw materials in the manufacture of industrial staples (steel, nonferrous metals, cardboard and paper, products from polymers, textile and wood materials, petrochemicals, building materials);

- sustainable use of natural raw materials, fuel and energy;

- less production and consumption waste footprint due to its active use in the circular economy;

- new jobs at treatment and recycling facilities: waste sorting facilities, manufacturers from recycled raw materials, stationary and mobile collection points from individuals and businesses;

- better conditions for networking with the global community in the areas of waste collection and treatment.

The extra regulatory instruments aimed at supplementing the federal law on secondary materials can be:

- guidelines with the criteria of classifying man-made waste as secondary materials;

- codifier and catalog of secondary materials;

- procedure and rules governing secondary raw materials management;

- procedure and standards for the collection, treatment and use of secondary materials;

- certification of secondary materials and recycled products;

- guidelines on the standards and measuring secondary materials accumulation;

- The public standard GOST "Secondary material resources. Terms and Definitions";

- drawing up new data and technical references and a common database on technologies for the use of secondary materials.

\section{References}

1. E.S. Tskhovrebov, ECOS, 3, 13 (2008)

2. V.V. Kutsenko, E.S. Tskhovrebov, S.N. Sidorenko, M.P. Tserenova, A.A. Kirichuk, Bull. Of RUDN Univ., 2, 75 (2013)

3. E.S. Tskhovrebov, S.V. Sadova, Bull. Of the Russ. Academ. Of Nat. Scienc., 2, 57 (2014)

4. E.V. Barishevsky, E.G. Velichko, E.S. Tskhovrebov, U.D. Niyazgulov, Bull. Of Moscow St. Univ. of Civ. Eng., 12, 260 (2017)

5. A.S. Shevchenko, U.D. Niyazgulov, E.S. Tskhovrebov, Kach. Innov. Obraz., 12, 34 (2017)

6. A.I. Zvyagina, Techn. Of Mech. Engen., 4, 50 (2007)

7. R.F. Sagitov, News of Orenb. St. Agr. Univ., 2, 246 (2015)

8. P.N. Chepiga, Probl. Of Mod. Econ., 4, 45 (2010)

9. A.A. Alekseev, Econ. I Upr., 4, 12 (2013)

10. T. Ludwig, Suts. Develop. Law, 16, 26 (2016) 